\title{
Programa Diagnóstico Amigo da Criança
}

\author{
Carneiro-Sampaio, Magda; Almeida, Mariana Nutti de; Takanori, Pedro; Leal, \\ Marta Miranda; Valente, Marcelo; Grassi, Marcília Sierro; Carlessi, Eliana Rodrigues \\ Instituto da Criança - HCFMUSP, São Paulo - SP - Brasil - magdascs@usp.br
}

INTRODUÇÃO: Preocupados com o impacto negativo dos procedimentos diagnósticos para pacientes pediátricos, um grupo de médicos e enfermeiras, decidiram propor (e por em prática) um programa que foi denominado "Diagnóstico Amigo da Criança", cujo objetivo principal é racionalizar o emprego dos métodos diagnósticos (de imagem, laboratório clínico e testes funcionais) na prática pediátrica, para que tragam o máximo de benefícios, o mínimo de riscos atuais e futuros, e que poupem a criança e 0 adolescente de sofrimento físico e agravos psicológicos evitáveis. OBJETIVOS: o Programa tem três grandes objetivos específicos: i) redução da quantidade de sangue coletada para as diferentes análises laboratoriais, que representa hoje a principal causa de transfusão de sangue em crianças de baixa idade internadas em hospitais. Estão sendo implantados micrométodos que reduzirão em até $75 \%$ a quantidade de sangue a ser colhida para os exames mais solicitados; ii) redução da exposição da criança à radiação ionizante, representada na prática sobretudo pelo raio $\mathrm{X}$, cujos princípios físicos são utilizados para gerar imagens não apenas nas radiografias convencionais e contrastadas, mas também na tomografia computadorizada, que emprega doses muito mais elevadas de radiação; iii) redução da necessidade de anestesia e mesmo de sedação em pré-escolares e escolares, através de medidas voltadas para o acolhimento e bem-estar da criança. MÉTODOS: Microcoleta com a implantação do tubo MiniCollect $\circledast$ da Greiner bio-one para o coagulograma $(0,8 \mathrm{ml})$ e hemograma $(0,5 \mathrm{ml})$. a realização na seringa heparinizada $(0,5 \mathrm{ml})$ do ionograma, glicemia e gasometria. para a implantação dessa microcoleta os equipamentos analíticos foram calibrados para volumes menores de sangue. o tomógrafo tem recurso de fornecer imagens detalhadas com quantidades expressivamente menores de radiação ionizante, quando comparado aos aparelhos tradicionais. RESULTADOS: Podemos observar a redução de $50 \%$ e $75 \%$ do volume retirado para a realização do hemograma e do coagulograma respectivamente. Estudos estão sendo realizados para analisar o impacto da implantação do Programa sobre o número de transfusões, o tempo de internação e a morbi-mortalidade, devendose fazer uma comparação com períodos imediatamente anteriores à implantação dos micrométodo. nos últimos 12 meses, com a ambientação da sala de Tomografia, 40\% em média dos exames solicitados com anestesia foram realizados sem necessidade de utilização de anestésico ou sedação, o que é desejável conforme esse Programa. CONCLUSÃO: Programa visa assim à humanização dos procedimentos diagnósticos, à segurança do paciente, à racionalização dos recursos diagnósticos, tem caráter educativo para profissionais da saúde e para a população. Tem a preocupação de resgatar os valores da anamnese e do exame físico, que vêm perdendo espaço para os exames complementares, em detrimento da qualidade do atendimento médico e do custeio da saúde.

Carneiro-Sampaio, Magda; Almeida, Mariana Nutti de; Takanori, Pedro; Leal, Marta Miranda; Valente, Marcelo; Grassi, Marcília Sierro; Carlessi, Eliana Rodrigues. Programa Diagnóstico Amigo da Criança. In: Anais do Congresso Internacional de Humanidades \& Humanização em Saúde [= Blucher Medical Proceedings, num.2, vol.1]. São Paulo: Editora Blucher, 2014. ISSN 2357-7282

DOI 10.5151/medpro-cihhs-10457 